\title{
Electrochemically modified Corey-Fuchs reaction for the synthesis of arylalkynes. The case of 2-(2,2-dibromovinyl)naphthalene
}

\author{
Fabiana Pandolfi, Isabella Chiarotto and Marta Feroci ${ }^{*}$
}

\author{
Full Research Paper \\ Address: \\ Deptartment of Fundamental and Applied Sciences for Engineering \\ (SBAI), Sapienza University of Rome, via Castro Laurenziano, 7 , \\ 00161, Rome, Italy \\ Email: \\ Marta Feroci* - marta.feroci@uniroma1.it \\ * Corresponding author \\ Keywords: \\ arylalkyne; carbon-bromine bond cleavage; cathodic reduction; \\ Corey-Fuchs reaction; 2-(2,2-dibromovinyl)naphthalene
}

\author{
Beilstein J. Org. Chem. 2018, 14, 891-899. \\ doi:10.3762/bjoc. 14.76 \\ Received: 27 December 2017 \\ Accepted: 12 April 2018 \\ Published: 23 April 2018 \\ This article is part of the Thematic Series "Electrosynthesis II". \\ Guest Editor: S. R. Waldvogel \\ (c) 2018 Pandolfi et al.; licensee Beilstein-Institut. \\ License and terms: see end of document.
}

\begin{abstract}
The electrochemical reduction of 2-(2,2-dibromovinyl)naphthalene in a DMF solution (Pt cathode) yields selectively 2-ethynylnaphthalene or 2-(bromoethynyl)naphthalene in high yields, depending on the electrolysis conditions. In particular, by simply changing the working potential and the supporting electrolyte, the reaction can be directed towards the synthesis of the terminal alkyne $\left(\mathrm{Et}_{4} \mathrm{NBF}_{4}\right)$ or the bromoalkyne $\left(\mathrm{NaClO}_{4}\right)$. This study allowed to establish that 2-(bromoethynyl)naphthalene can be converted into 2-ethynylnaphthalene by cathodic reduction.
\end{abstract}

\section{Introduction}

Terminal alkynes, due to the considerable triple-bond strength $\left(839 \mathrm{~kJ} \mathrm{~mol}^{-1}\right)$, are characterized by a moderate thermodynamic reactivity [1]. Nevertheless, both the $\mathrm{C}-\mathrm{C}$ triple bond and the terminal $\mathrm{C}-\mathrm{H}$ bond can be efficiently and selectively activated by metal or metal-free catalysts. Therefore, terminal alkynes can be considered as raw material (thus an important resource).

The use of terminal alkynes, activated by catalysts, as building blocks or intermediates in the synthesis of a large number of chemicals is extensively summarized in recent reviews [1-3].
The recently published papers confirm the present interest in the chemistry of terminal alkynes, e.g., in the synthesis of sulfinamides and isothiazoles [4], 1,3-enynes [5], $\alpha$-monosubstituted propargylamines [6], 2-substituted pyrazolo[5,1-a]isoquinolines [7], etc.

Terminal alkynes can be prepared by dehydrohalogenation of vicinal dihalides or vinyl bromides using sodium in ammonia or strong bases [8]. Alternatively, the compounds are accessible by homologation of aldehydes following the Bestmann modification of the Seyferth-Gilbert reaction, using in situ generated 
dimethyl (diazomethyl)phosphonate [9,10]. Moreover, the aldehyde homologation to terminal alkynes can also be obtained using the Corey-Fuchs reaction [11]. This is a two-step reaction in which an aldehyde is at first converted into a 1,1-dibromoalkene with chain extension by one carbon atom through the reaction with carbon tetrabromide and triphenylphosphine (Scheme 1, reaction 1). The second step comprises the conversion of the 1,1-dibromoalkene into the corresponding alkyne by reaction with BuLi at $-78{ }^{\circ} \mathrm{C}$ in THF (Scheme 1, reaction 2) [12].

Recently, a chemical modification of the second step of the Corey-Fuchs reaction was reported, in which the authors used $\mathrm{Cs}_{2} \mathrm{CO}_{3}$ as the base and performed the reaction in DMSO at $115{ }^{\circ} \mathrm{C}$ for $12 \mathrm{~h}$ [13]. Good to high yields of terminal alkynes were obtained (50-98\%). Also DBU (4 equiv) in $\mathrm{MeCN}$ at room temperature is effective to carry out the second step of the Corey-Fuchs reaction, affording good to high yields of arylalkynes. In the latter reaction DBU acts both as base and as organocatalyst [14]. In all cases, an excess of a strong base or high temperature are necessary for the reaction to proceed. An overview on the importance of the Corey-Fuchs reaction for the synthesis of natural products has been pointed out by Heravi and co-workers recently [15].

As mentioned above the second step of the Corey-Fuchs reaction requires the cleavage of a $\mathrm{C}-\mathrm{Br}$ bond. We thus envisaged if this could be achieved electrochemically via a selective cathodic cleavage of the $\mathrm{C}-\mathrm{Br}$ bond. In this way, the reaction could be performed under mild conditions and in the absence of reducing agents or bases in the reaction mixture.

Electrochemical methods can be considered an environmentally friendly technique: they rely on the use of practically massless electrons (which are not converted to byproducts) instead of stoichiometric amounts of redox reagents and frequently these reactions are carried out at room temperature and at atmospheric pressure, etc. [16-19].

The electrochemical behavior of halogenated compounds has been extensively investigated [20-22]. The cleavage of the $\mathrm{C}-$ halogen bond, yielding (via a radical intermediate) the corresponding carbanion and halogen anion, can be achieved by a bielectronic cathodic process (Scheme 2). The electrolysis is carried out at a suitable controlled potential, i.e., at a potential that is negative enough to achieve the selective fission of the envisaged C-halogen bond [23].

Therefore, the reactive species is an electrochemically generated carbanion and the outcome of the reaction strongly depends on the complex reactivity of this intermediate. Moreover, this reactivity is influenced by the reaction conditions, such as the solvent, supporting electrolyte, electroinactive substrates, temperature, working potential and amount of consumed charge [24].

Our group intensively investigated the electrochemical behavior of 1,1-dibromoalkenes by means of cyclic voltammetry and
(1)

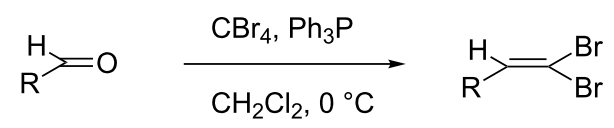

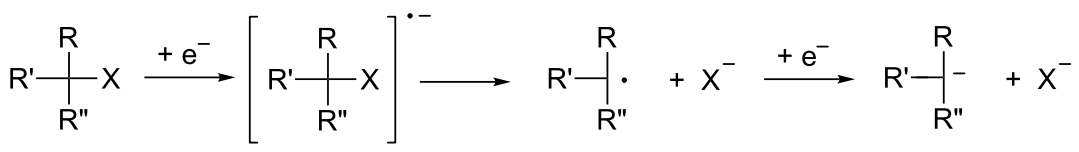

$\mathrm{X}$ : halogen 
electrolyses [25] and we reported the selective synthesis of vinyl bromides through the cathodic reduction of 1,1-dibromoalkenes in the presence of acetic acid. The electrolysis conditions in this transformation were optimized in order to avoid or minimize the formation of the terminal alkyne. The latter was obtained as the major product in the absence of a proton donor and its formation could be suppressed when performing the reaction with a $\mathrm{Au}$ cathode in acetonitrile $(\mathrm{ACN})$ as the solvent and in the presence of an excess of acetic acid as the proton source. Under these conditions good yields of the vinyl bromides were obtained with preference of the $\mathrm{Z}$-isomers (Scheme 3).

$$
\begin{aligned}
& \mathrm{R}_{\mathrm{Br}}^{\mathrm{H}}>=<_{\mathrm{Br}}^{\mathrm{Br}} \stackrel{+\mathrm{e}^{-} \text {Au cathode }}{\underset{\mathrm{AcOH}}{\mathrm{CH}_{3} \mathrm{CN}, \mathrm{Et}_{4} \mathrm{NClO}_{4}}} \underset{\mathrm{R}}{\mathrm{H}}>=<_{\mathrm{Br}}^{\mathrm{H}} \\
& Z / E \approx 80: 20
\end{aligned}
$$

Scheme 3: Electrochemical synthesis of vinyl bromides [25].

We have now reconsidered this investigation in order to obtain terminal alkynes and to avoid the formation of vinyl bromides. The scope of this paper is the determination of the electrolysis conditions for the transformation of 1,1-dibromoalkenes into the corresponding terminal alkynes, in order to carry out the second step of the Corey-Fuchs reaction under milder conditions.

2-Ethynylnaphthalene (2a) is a small molecule with a high and selective biological activity. In particular, this molecule has been demonstrated to be a selective inactivator of cytochrome P-450 2B4 [26] and an inhibitor also of other cytochrome P-450 isoforms [27]. We thus decided to carry out our study using 2-(2,2-dibromovinyl)naphthalene (1a) as starting material for the synthesis of 2-ethynylnaphthalene (2a, Scheme 4).

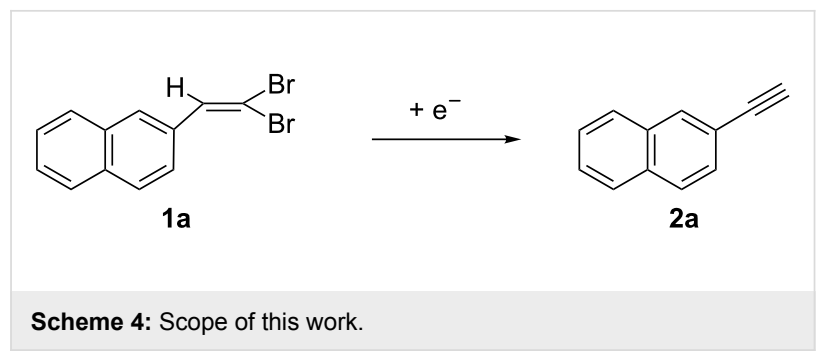

\section{Results and Discussion}

In our previous work [25], we found that the cathodic reduction of 2-(2,2-dibromovinyl)naphthalene (1a), carried out at the potential of the first voltammetric peak in ACN on a $\mathrm{Au}$ cathode and in the presence of an excess acetic acid, yielded the corresponding vinyl bromides (Scheme 3) in 75\% yield (Z/E 82:18). The main product was 2-ethynylnaphthalene (2a, $65 \%$ ) when the electrolysis was carried out in the absence of acetic acid as protonating agent ( $1.8 \mathrm{~F}$ consumed charge). Due to the importance of the latter product, we decided to reconsider this procedure in order to direct the synthesis towards the formation of the alkyne. We have therefore reconsidered the voltammetric behavior of 1a at Pt, Ag and GC cathodes in DMF or ACN solutions (Figure 1).
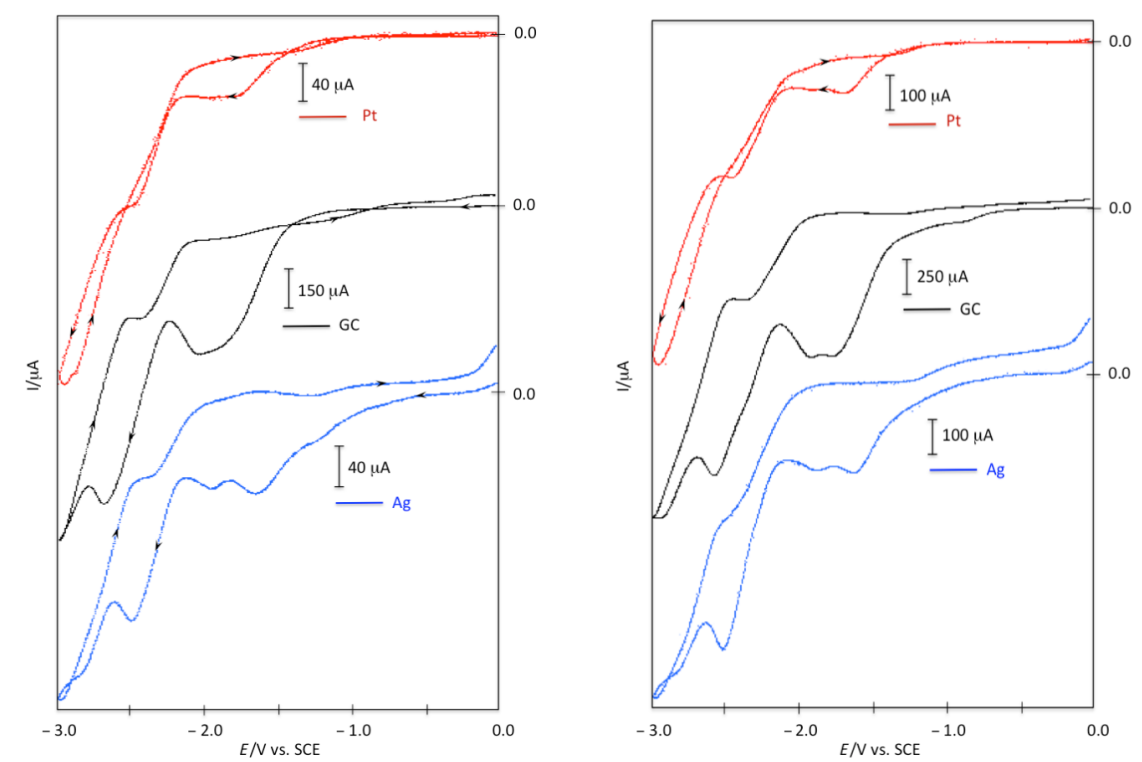

Figure 1: Voltammetric curves of 1a $0.020 \mathrm{~mol} \mathrm{dm}^{-3}$; Pt, glassy carbon (GC) or Ag cathode. $v=0.2 \mathrm{~V} \mathrm{~s}^{-1}, T=25^{\circ} \mathrm{C}$; solvent left: $\mathrm{DMF} / \mathrm{Et} \mathrm{NBF}_{4}$ $0.1 \mathrm{~mol} \mathrm{dm}{ }^{-3}$; right: $\mathrm{ACN} / \mathrm{Et}_{4} \mathrm{NBF}_{4} 0.1 \mathrm{~mol} \mathrm{dm}^{-3}$. 
The voltammetric curves of 1a show the presence of different reduction peaks which are affected by the solvent and by the electrode material (see peak potential Table S1 in Supporting Information File 1). These voltammograms (and the data reported in Supporting Information File 1, Table S1) evidence the catalytic effect of the silver cathode in the $\mathrm{C}-\mathrm{Br}$ bond reduction ( $E_{\mathrm{p} 1}$ is quite less negative on $\mathrm{Ag}$ cathode) [28,29], although this effect is more evident in DMF than in ACN. In any voltammogram, the cathodic peak at the less negative potential should be related to the cleavage of the $\mathrm{C}-\mathrm{Br}$ bond. In order to confirm this statement, we carried out a first electrolysis in acetonitrile on a Pt cathode at the controlled potential of $-1.75 \mathrm{~V}$ vs SCE, corresponding to the first reduction wave of $\mathbf{1 a}$ (Table 1, entry 1). The current flow was stopped after the disappearance of $1 \mathbf{a}(6.0 \mathrm{~F})$. The only product was the expected alkyne 2a (Scheme 4) with $69 \%$ yield. This result was in accordance with what reported in our previous work using a Au cathode (but with a much lower current efficiency - probably due to side reactions - when compared to the result obtained using a $\mathrm{Au}$ cathode in the previous paper) [25].

In order to ascertain the role of the solvent in this electrosynthesis, we carried out an electrolysis in DMF instead of ACN on a Pt cathode at the controlled potential of $-2.00 \mathrm{~V}$ vs SCE, corresponding to the first reduction wave of $\mathbf{1 a}$ (Table 1, entry 2). The current flow was stopped after the disappearance of 1a $(3.0 \mathrm{~F})$. Also in this case the only product was the expected alkyne 2a with a higher yield (80\%).

An increase in the charge did not lead to an increase of the yield ( $81 \%$, Table 1 , entry 3 ). When the working potential was increased to $-1.75 \mathrm{~V}$ and the electrolysis was stopped after the total consumption of $1 \mathrm{a}(1.5 \mathrm{~F})$, a mixture of products was obtained (Scheme 5 and Table 1, entry 4). In particular, a large amount (48\%) of the brominated alkyne 3a was isolated, along with traces of hydrogenated alkene $\mathbf{4 a}$. In order to confirm the

\begin{tabular}{|c|c|c|c|c|c|c|c|}
\hline \multirow[t]{2}{*}{ entry } & \multirow[t]{2}{*}{ cathode } & \multirow[t]{2}{*}{$E$ or $l^{b}$} & \multirow[t]{2}{*}{$\mathrm{F}^{\mathrm{C}}$} & \multicolumn{4}{|c|}{ products $(\%)^{\mathrm{d}}$} \\
\hline & & & & $2 a$ & $3 a$ & $4 a$ & $5 a$ \\
\hline $1^{e}$ & $\mathrm{Pt}$ & $-1.75 \mathrm{~V}$ & 6.0 & 69 & - & - & - \\
\hline 2 & $\mathrm{Pt}$ & $-2.00 \mathrm{~V}$ & 3.0 & 80 & - & traces & traces \\
\hline 3 & $\mathrm{Pt}$ & $-2.00 \mathrm{~V}$ & 4.0 & 81 & - & traces & - \\
\hline 4 & $\mathrm{Pt}$ & $-1.75 \mathrm{~V}$ & 1.5 & 25 & 48 & 4 & traces \\
\hline $5^{f}$ & $\mathrm{Pt}$ & $-1.75 \mathrm{~V}$ & 2.3 & 27 & - & - & $58^{g}$ \\
\hline 6 & $\mathrm{Pt}$ & $10 \mathrm{~mA} / \mathrm{cm}^{2}$ & 3.0 & 46 & - & 41 & - \\
\hline 7 & $\mathrm{Pt}$ & $5 \mathrm{~mA} / \mathrm{cm}^{2}$ & 3.0 & 29 & - & 39 & - \\
\hline 8 & GC & $-1.70 \mathrm{~V}$ & 0.6 & 5 & 7 & - & 7 \\
\hline 9 & $\mathrm{Ag}$ & $-1.80 \mathrm{~V}$ & 3.0 & 72 & - & 6 & - \\
\hline 10 & $\mathrm{Ag}$ & $-2.10 \mathrm{~V}$ & 3.0 & 65 & - & 15 & 2 \\
\hline $11^{\mathrm{h}}$ & $\mathrm{Pt}$ & $-2.20 \mathrm{~V}$ & 2.0 & 7 & 89 & - & - \\
\hline $12^{\mathrm{h}}$ & $\mathrm{Pt}$ & $-2.20 \mathrm{~V}$ & 3.0 & 43 & 38 & - & - \\
\hline
\end{tabular}

aElectrolysis conditions: divided cell, $5.0 \mathrm{~mL}$ of DMF (catholyte)/0.1 mol dm ${ }^{-3} \mathrm{Et}_{4} \mathrm{NBF}_{4}$ containing $1 \mathrm{a}(0.5 \mathrm{mmol})$, rt, $\mathrm{N}_{2}$ atmosphere. Anolyte: $2.0 \mathrm{~mL}$ same solvent. Working electrode: as in Table; anode: Pt; reference electrode: modified SCE (see Supporting Information File 1). The electrolyses were stopped after total consumption of starting 1a. ${ }^{b}$ Controlled potential electrolyses: working potential $E$ (Volts) reported vs SCE. Controlled current electrolyses: working current density $I\left(\mathrm{~mA} / \mathrm{cm}^{2}\right)$ reported. ${ }^{\mathrm{C}}$ Amount of charge: number of Faradays. ${ }^{\mathrm{d}}$ Isolated yields, with respect to starting $1 \mathrm{a}$. ${ }^{\mathrm{e}} \mathrm{ACN}$ instead of DMF as solvent. ${ }^{3} 3$ Equivalents of acetic acid were present in the catholyte during electrolysis. ${ }^{9}$ Mixture of isomers: $\mathrm{Z} / E=69: 31$. $\mathrm{h}_{\mathrm{NaClO}}$ instead of $\mathrm{Et}_{4} \mathrm{NBF}_{4}$ as supporting electrolyte.

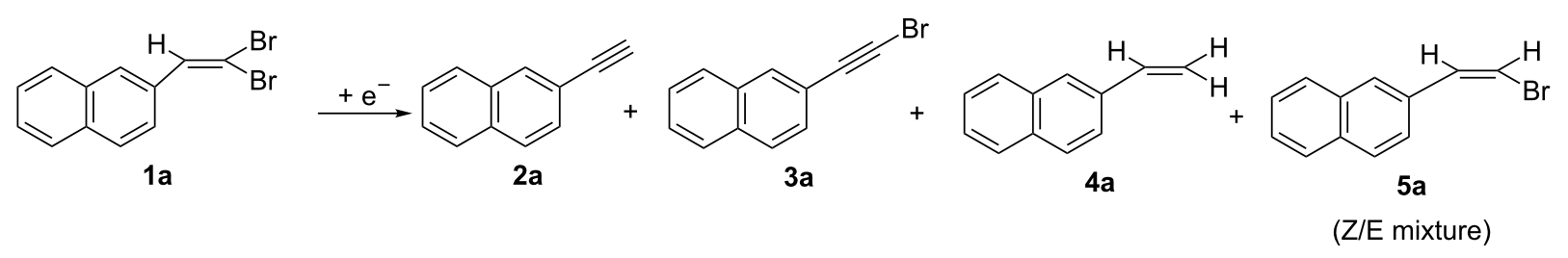


effect of the presence of a proton donor, acetic acid was added to the solution and the electrolysis was carried out at the first cathodic peak potential (Table 1, entry 5). After 2.3 F (total consumption of starting material), the alkyne 2 a was isolated in $27 \%$ yield, while the major product was bromoalkene 5a (mixture of $Z$ and $E$ isomers) in 58\% yield. This result is very similar to what we reported in our previous work [25].

Also the electrochemical methodology has a dramatic effect on the products of the cathodic reduction of 1a. In fact, carrying out the electrolysis under controlled current conditions (Table 1, entry 6) equimolar amounts of desired alkyne 2a and of vinyl derivative 4a (Scheme 5) were obtained when a current density of $10 \mathrm{~mA} / \mathrm{cm}^{2}$ was used, while lowering the current density to $5 \mathrm{~mA} / \mathrm{cm}^{2}$ did not alter significantly the reaction outcome (Table 1, entry 6 vs 7).

It is well known that the electrode material could influence the outcome of an electrosynthesis, so we carried out electrolyses of 1a using a glassy carbon cathode (Table 1, entry 8) and a silver cathode (Table 1, entry 9). In both cases the working potential was that of the first reduction wave. In the case of glassy carbon, the electrolysis could not be terminated as the current flow stopped very early [30]. When a silver cathode was used, a good yield of desired alkyne 2a was obtained (72\%), along with a small amount of hydrogenated alkene $4 \mathbf{a}(6 \%)$. In order to increase the yield of alkyne $\mathbf{2 a}$ (and as $\mathbf{2 a}$ reduction potential is much more negative, vide infra), we carried out a cathodic reduction of 1a on a silver cathode at the second reduction wave potential (Table 1, entry 10). In this last case, the selectivity of the reaction dropped and a notable amount of hydrogenated alkene $4 \mathbf{a}$ was obtained (15\%), along with a lower yield of alkyne 2a (65\%).

The effect of a different supporting electrolyte was evaluated by substitution of $\mathrm{Et}_{4} \mathrm{NBF}_{4}$ with $\mathrm{NaClO}_{4}$. Also in this case the electrolysis was stopped after the complete consumption of starting 1a (Table 1, entry 11). The change in supporting electrolyte led to a complete change in products. In fact, a very high yield of 2-(bromoethynyl)naphthalene (3a) was obtained (89\%), along with only $7 \%$ of 2-ethynylnaphthalene (2a) after $2.0 \mathrm{~F}$. Increasing the consumed charge to $3.0 \mathrm{~F}$ under the same experimental conditions, an equimolar mixture of bromoalkyne $\mathbf{3 a}$ and alkyne 2a was obtained, confirming the possibility of obtaining $\mathbf{2 a}$ by cathodic reduction of $\mathbf{3 a}$ (Table 1, entry 11 vs 12 ).

In order to better understand the electrochemical behavior of dibromoalkene 1a, we carried out the voltammetric analysis of all isolated products (see Supporting Information File 1). The first cathodic peak potential of 2-(bromoethynyl)naphthalene (3a, Scheme 5) is very close to the first cathodic peak potential of 2-(2,2-dibromovinyl)naphthalene (1a), irrespective of the solvent and working electrode material. This renders impossible a selective cathodic reduction of $\mathbf{1 a}$ in the presence of $\mathbf{3 a}$. The voltammetric behavior of 2-ethynylnaphthalene (2a) shows only one reduction peak at a potential that is quite more negative than the first cathodic peak of $\mathbf{1 a}$ and 3a, respectively, and corresponding to the third reduction peak of $\mathbf{1 a}$ and to the second of 3a. Also in this case the potential value is independent of the solvent and working electrode material. This voltammetric analysis shows that the cathodic reduction of both $\mathbf{1 a}$ and 3a could lead to the formation of the desired alkyne $\mathbf{2 a}$.

To ascertain this hypothesis and to get information on the nature of the intermediates of the electrochemical process, we carried out the electrosynthesis under the optimized experimental conditions reported in Table 1, entry 2, analyzing the catholyte during the electrolysis. The yields of electrolysis products $\mathbf{2 a}$ and 3a were reported as a function of the number of Faraday (Figure 2).

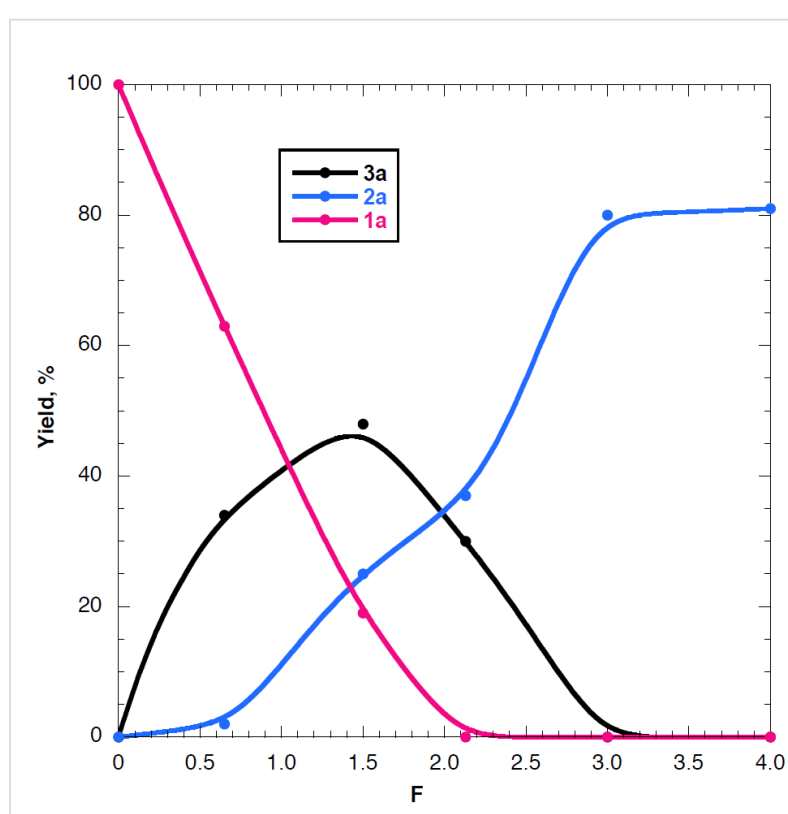

Figure 2: Variation of the amounts of $\mathbf{1 a}, \mathbf{2 a}$, and $\mathbf{3 a}$ with the number of Faradays of $1 \mathbf{a}$.

The results of this last investigation (curves reported in Figure 2) show that i) the concentration of 1 a decreases and that of 2a increases with increasing charge; ii) dibromoalkene $\mathbf{1 a}$ is completely reduced after a consumption of $2.0 \mathrm{~F}$, i.e., a value of charge near the theoretical value for the bielectronic reduction of a C-Br bond; iii) after a consumption of $2.0 \mathrm{~F}$ the yield of alkyne $2 \mathrm{a}$ is $40 \%$ versus a yield of $80 \%$ after $3.0 \mathrm{~F}$; iv) the analysis of the solution during the electrolysis shows the presence of bromoalkyne $\mathbf{3 a}$. 
The concentration of $\mathbf{3 a}$ initially increases and subsequently decreases upon increasing the charge; bromoalkyne 3a is absent in the final solution. The maximum yield of $\mathbf{3 a}$, close to $50 \%$, is reached after the consumption of about $1.5 \mathrm{~F}$.

Bromoalkyne 3a and alkyne 2a seem to be strictly related. In fact, the increase of $\mathbf{3 a}$ corresponds to the decrease of starting 1a, while the subsequent decrease of $\mathbf{3 a}$ corresponds to the increase of 2a. In addition the analysis of the electrolyzed solutions shows the presence of only a trace amount of vinyl bromide 5a. Note that vinyl bromide $\mathbf{5 a}$ is cathodically active at the working potential (see Supporting Information File 1). The overall analysis allows suggesting a mechanistic hypothesis (Scheme 6).

The bielectronic cathodic reduction of dibromoalkene 1a leads to the cleavage of one $\mathrm{C}-\mathrm{Br}$ bond and the formation of the corresponding vinyl anion (Scheme 6, reaction 1). An equilibrium of proton exchange between this electrogenerated carbanion and parent 1a yields vinylbromide 5a and a second vinyl anion (Scheme 2, reaction 2), which is converted to bromoalkyne 3a by bromide elimination. Vinyl bromide $\mathbf{5 a}$ can be cathodically reduced to 2-vinylnaphthalene (4a) or eliminate $\mathrm{HBr}$ to yield alkyne $\mathbf{2 a}$.
Bromoalkyne 3a then can be reduced at the electrode to yield alkyne 2a. The presence of a proton donor (Table 1, entry 5 ) increases the yield of $\mathbf{5 a}$ and substitutes $\mathbf{1 a}$ (as proton donor) in reaction 2 (Scheme 6).

The anion generated by cathodic reduction of dibromoalkene 1a (Scheme 2, reaction 1) can also eliminate bromide (as reported in literature [31]), yielding the corresponding carbene (Scheme 2, reaction 2). This carbene can undergo a rearrangement to yield alkyne 2a. According to the mechanism shown in Scheme 6 , the formation of bromoalkyne $\mathbf{3 a}$ competes with the formation of $2 \mathbf{a}$ in reaction 2 and its rate of formation is comparable to that of $2 \mathbf{a}$. Since its reduction potential is close to that of 1a (see Supporting Information File 1, Table S1 and Figure $\mathrm{S} 2$ ), it is further reduced to the alkyne $\mathbf{2 a}$ (reaction 3 in Scheme 6) during the electrolysis.

The various possible ways described in Scheme 6 are highly influenced by the reaction conditions. When the supporting electrolyte is $\mathrm{NaClO}_{4}$ instead of $\mathrm{Et}_{4} \mathrm{NBF}_{4}$, a different mechanism seems to be operative. In fact, following reactions (1) and (2) in Scheme 6, a maximum yield of $50 \%$ of $\mathbf{3 a}$ can be obtained. It is thus possible that when using $\mathrm{NaClO}_{4}$ an electrogenerated base $\left(\mathrm{OH}^{-}\right)$is formed, due to the reduction of water

(1)

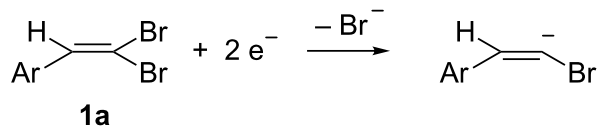

1a

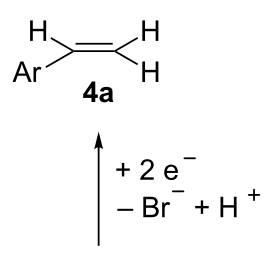

(2)
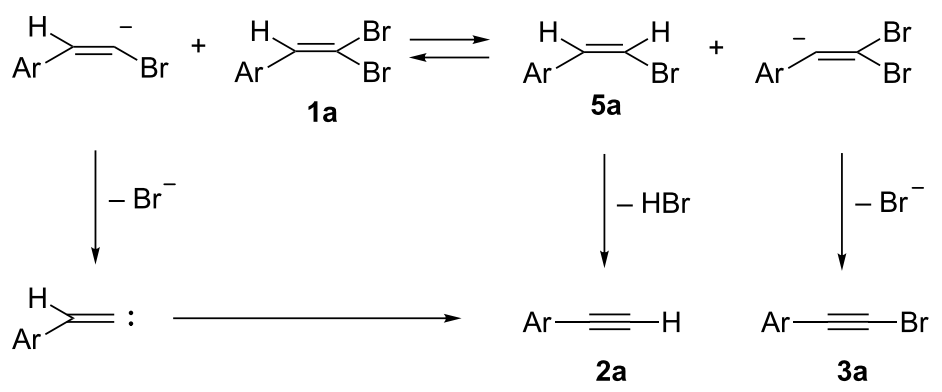

(3)

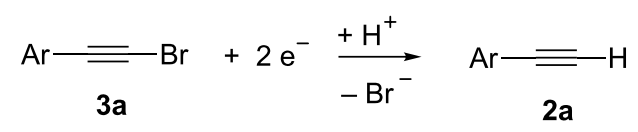


and this base converts 1a to $\mathbf{3 a}$. In fact, the $\mathrm{Na}^{+}$cation is highly hydrophilic while the $\mathrm{Et}_{4} \mathrm{~N}^{+}$cation is hydrophobic. Thus, in $\mathrm{DMF} / \mathrm{NaClO}_{4}$ the double layer would be constituted by the strongly solvated $\mathrm{Na}^{+}\left(\mathrm{H}_{2} \mathrm{O}\right)_{n}$, while in $\mathrm{DMF} / \mathrm{Et}_{4} \mathrm{NBF}_{4}$, the double layer would be free of water. On Pt, a low hydrogen overvoltage material, it is then conceivable that the reduction of water to dihydrogen and hydroxide anions would be faster than the reduction of 1a. The overall reaction would be a one-electron process catalyzed by water reduction (Scheme 7) [32].

It is thus possible by selecting the electrolysis conditions to synthesize selectively 2-ethynylnaphthalene (2a, Table 1 , entry 2) or 2-(bromoethynyl)naphthalene (3a, Table 1, entry 11) in high yields.

Finally, to test the general applicability of the proposed electrochemical methodology, we submitted to electrolysis (under the optimized conditions reported in Table 1, entry 2), 3-(2,2dibromovinyl)-9-ethyl-9H-carbazole (1b, Scheme 8 ). In fact, the corresponding alkyne $\mathbf{2 b}$ is an important intermediate in the synthesis of molecules for organic electronics (e.g., organic light-emitting diodes [33] and organic field-effect transistors [34]). The voltammetric analysis showed a behavior similar to that of 1a (see Supporting Information File 1) and thus the electrolysis was carried out at the second wave potential. 9-Ethyl-3ethynyl-9H-carbazole (2b) was obtained in $77 \%$ yield.

Similarly, when starting from 1-(2,2-dibromovinyl)-4-methoxybenzene (1c), the corresponding terminal alkyne $2 \mathrm{c}$ was obtained in $62 \%$ yield (Scheme 9).

\section{Conclusion}

The electrochemical methodology is shown to be a useful tool in organic synthesis. The possibility to direct the reaction

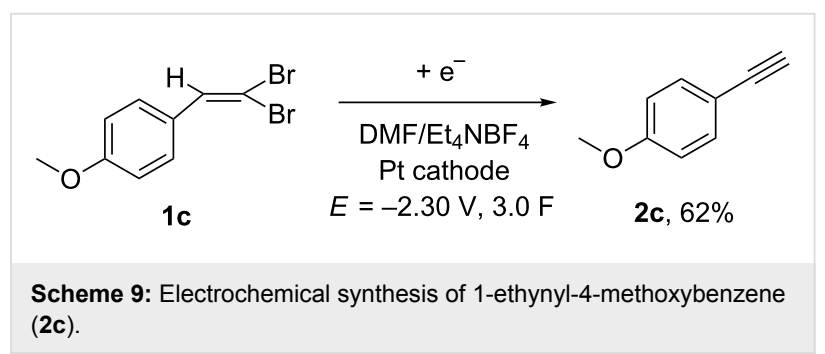

towards different products simply by changing the electrolysis parameters (potential, solvent, supporting electrolyte, amount of charge, additives, etc.) and making use of electrons (as green, cheap, no byproduct-forming reagents) renders electrosynthesis attractive for organic chemists.

In particular, this work reported the selective synthesis of 2-ethynylnaphthalene or 2-(bromoethynyl)naphthalene in high yields by the cathodic reduction of 2-(2,2-dibromovinyl)naphthalene. The electrolyses were carried out in DMF solution (Pt cathode) under potentiostatic conditions; if the potential was fixed at $-2.00 \mathrm{~V}$ (vs SCE) and the supporting electrolyte was $\mathrm{Et}_{4} \mathrm{NBF}_{4}$, and 2-ethynylnaphthalene was obtained in $80 \%$ yield after 3.0 F, while using $\mathrm{NaClO}_{4}$ as salt and a potential of $-2.20 \mathrm{~V} 2$-(bromoethynyl)naphthalene was obtained in $89 \%$ yield after $2.0 \mathrm{~F}$. We also demonstrated that 2-(bromoethynyl)naphthalene can be cathodically converted to 2-ethynylnaphthalene. The extension of the method to two other substrates was successfully demonstrated. This methodology allows carrying out the second step of the Corey-Fuchs reaction under milder experimental conditions.

\section{Experimental}

Electrolyses. Constant potential or current electrolyses were performed under a nitrogen atmosphere at $25^{\circ} \mathrm{C}$ using an Amel<smiles>BrC(Br)=Cc1ccc2ccccc2c1</smiles>

$1 \mathrm{a}$<smiles>BrC#Cc1ccc2ccccc2c1</smiles>

$3 a$

Scheme 7: Possible reaction using $\mathrm{NaClO}_{4}$ as supporting electrolyte.
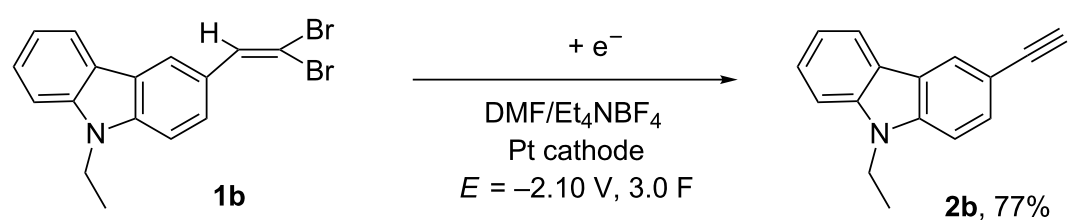

Scheme 8: Electrochemical synthesis of 9-ethyl-3-ethynyl-9H-carbazole (2b). 
2053 potentiostat-galvanostat equipped with an Amel 731 integrator. All experiments were carried out in a divided glass cell separated through a porous glass plug filled with a layer of gel (i.e., methyl cellulose 0.5 vol \% dissolved in $\mathrm{DMF} / \mathrm{Et}_{4} \mathrm{NBF}_{4}$, $1.0 \mathrm{~mol} \mathrm{dm}^{-3}$ ). Pt spirals (apparent area $0.8 \mathrm{~cm}^{2}$ ) were used as both cathode and anode, unless otherwise specified. Catholyte: $5 \mathrm{~mL}$ of DMF/0.1 M Et ${ }_{4} \mathrm{NBF}_{4}$; anolyte: $2 \mathrm{~mL}$ of the same solvent of catholyte. 2,2-Dibromovinylnaphthalene $(0.5 \mathrm{mmol})$ was present in the catholyte during electrolysis. The number of Coulombs and the electrolysis potential/current were varied as reported in the text. At the end of the electrolysis, the catholyte was poured in an excess of water and extracted with petroleum ether 40-60 $(3 \times 20 \mathrm{~mL})$. Flash column chromatography (eluent: petroleum ether/ethyl acetate from 100:0 to 90:10) gave purified products.

\section{Supporting Information}

\section{Supporting Information File 1}

Detailed experimental procedures, NMR spectra and cyclic voltammetries.

[https://www.beilstein-journals.org/bjoc/content/ supplementary/1860-5397-14-76-S1.pdf]

\section{Acknowledgements}

The authors acknowledge Sapienza University of Rome for financial support and Mr Marco Di Pilato for his help with the voltammetric analysis.

\section{ORCID ${ }^{\circledR}$ iDs}

Fabiana Pandolfi - https://orcid.org/0000-0002-5972-851X Isabella Chiarotto - https://orcid.org/0000-0001-7165-3226 Marta Feroci - https://orcid.org/0000-0002-3673-6509

\section{References}

1. Lei, J.; Su, L.; Zeng, K.; Chen, T.; Qiu, R.; Zhou, Y.; Au, C.-T.; Yin, S.-F. Chem. Eng. Sci. 2017, 171, 404-425. doi:10.1016/j.ces.2017.05.021

2. Chinchilla, R.; Nájera, C. Chem. Rev. 2014, 114, 1783-1826. doi:10.1021/cr400133p

3. Ackermann, L. Acc. Chem. Res. 2014, 47, 281-295. doi:10.1021/ar3002798

4. Rodríguez, M. R.; Beltrán, Á.; Mudarra, Á. L.; Álvarez, E.; Maseras, F.; Díaz-Requejo, M. M.; Pérez, P. J. Angew. Chem., Int. Ed. 2017, 56, 12842-12847. doi:10.1002/anie.201705664

5. Islas, R. E.; Cárdenas, J.; Gaviño, R.; García-Ríos, E.; Lomas-Romero, L.; Morales-Serna, J. A. RSC Adv. 2017, 7, 9780-9789. doi:10.1039/c6ra28855c

6. Takano, S.; Kochi, T.; Kakiuchi, F. Chem. Lett. 2017, 46, 1620-1623. doi:10.1246/cl.170754

7. Liu, H.; Lu, L.; Hua, R. Tetrahedron 2017, 73, 6428-6435. doi:10.1016/j.tet.2017.09.037
8. Campbell, K. N.; Campbell, B. K. Org. Synth.; Coll. Vol. 4; 1963; pp 763-766.

9. Müller, S. G.; Liepold, B.; Roth, G. J.; Bestmann, H. J. Synlett 1996, 521-522. doi:10.1055/s-1996-5474

10. Roth, G. J.; Liepold, B.; Müller, S. G.; Bestmann, H. J. Synthesis 2004, 59-62. doi:10.1055/s-2003-44346

11. Corey, E. J.; Fuchs, P. L. Tetrahedron Lett. 1972, 13, 3769-3772. doi:10.1016/S0040-4039(01)94157-7

12. Sahu, B.; Muruganantham, R.; Namboothiri, I. N. N. Eur. J. Org. Chem. 2007, 2477-2489. doi:10.1002/ejoc.200601137

13. Zhao, M.; Kuang, C.; Yang, Q.; Cheng, X. Tetrahedron Lett. 2011, 52, 992-994. doi:10.1016/j.tetlet.2010.12.071

14. Morri, A. K.; Thummala, Y.; Doddi, V. R. Org. Lett. 2015, 17, 4640-4643. doi:10.1021/acs.orglett.5b02398

15. Heravi, M. M.; Asadi, S.; Nazari, N.; Lashkariani, M. B. Curr. Org. Chem. 2015, 19, 2196-2219. doi:10.2174/1385272819666150619174010

16. Steckhan, E.; Arns, T.; Heineman, W. R.; Hilt, G.; Hoormann, D.; Jörissen, J.; Kröner, L.; Lewall, B.; Pütter, H. Chemosphere 2001, 43, 63-73. doi:10.1016/S0045-6535(00)00325-8

17. Frontana-Uribe, B. A.; Little, R. D.; Ibanez, J. G.; Palma, A.; Vasquez-Medrano, R. Green Chem. 2010, 12, 2099-2119. doi:10.1039/COGC00382D

18. Schäfer, H. J. C. R. Chim. 2011, 14, 745-765. doi:10.1016/j.crci.2011.01.002

19. Horn, E. J.; Rosen, B. R.; Baran, P. S. ACS Cent. Sci. 2016, 2, 302-308. doi:10.1021/acscentsci.6b00091

20. Casanova, J.; Reddy, V. P. Electrochemistry of the carbon-halogen bond. In The Chemistry of Functional Groups, Supplement D2; Patai, S.; Rappoport, Z., Eds.; Wiley: New York, 1995; pp 1003-1067.

21. Peters, D. G. Oxidation and reduction of halogen-containing compounds. In Encyclopedia of Electrochemistry; Schäfer, H. J., Ed.; Wiley-VCH Verlag GmbH: Weinheim, Germany, 2004; Vol. 8, pp 217-233.

22. Torii, S. Electroreduction of Halogenated Compounds. Electroorganic Reduction Synthesis; Wiley-VCH Verlag GmbH: Weinheim, Germany, 2006; Vol. 1, pp 331-432.

23. Peters, D. G. In Organic Electrochemistry, 5th ed.; Hammerich, O.; Speiser, B., Eds.; Taylor \& Francis, LLC: London, 2016; pp 941-980.

24. Martin, E. T.; McGuire, C. M.; Mubarak, M. S.; Peters, D. G. Chem. Rev. 2016, 116, 15198-15234. doi:10.1021/acs.chemrev.6b00531

25. Feroci, M.; Orsini, M.; Palombi, L.; Sotgiu, G.; Inesi, A. Electrochim. Acta 2004, 49, 635-640. doi:10.1016/j.electacta.2003.09.018

26. Strobel, S. M.; Szklark, G. D.; He, Y. Q.; Foroozesh, M.; Alworth, W. L.; Roberts, E. S.; Hollenberg, P. F.; Halpert, J. R. J. Pharmacol. Exp. Ther. 1999, 290, 445-451.

27. Beebe, L. E.; Roberts, E. S.; Fornwald, L. W.; Hollenberg, P. F.; Alworth, W. L. Biochem. Pharmacol. 1996, 52, 1507-1513. doi:10.1016/S0006-2952(96)00525-4

28. Mubarak, M. S.; Peters, D. G. Curr. Opin. Electrochem. 2017, 2, 60-66. doi:10.1016/j.coelec.2017.03.001

29. Gennaro, A.; Isse, A. A.; Mussini, P. R. In Organic Electrochemistry, 5th ed.; Hammerich, O.; Speiser, B., Eds.; Taylor \& Francis, LLC: London, 2016; pp 917-940.

30. The use of glassy carbon (GC) as cathode was not possible probably due to adsorption of material on the electrode surface, which led to electrical insulation. 
31. Abbas, S.; Hayes, C. J.; Worden, S. Tetrahedron Lett. 2000, 41, 3215-3219. doi:10.1016/S0040-4039(00)00353-1

32. We are grateful to a referee for suggesting this mechanistic hypothesis.

33. Li, Y.-P.; Fan, X.-X.; Wu, Y.; Zeng, X.-C.; Wang, J.-Y.; Wei, Q.-H.; Chen, Z.-N. J. Mater. Chem. C 2017, 5, 3072-3078.

doi:10.1039/c7tc00382j

34. Kato, S.-i.; Noguchi, H.; Kobayashi, A.; Yoshihara, T.; Tobita, S.; Nakamura, Y. J. Org. Chem. 2012, 77, 9120-9133.

doi:10.1021/jo3016538

\section{License and Terms}

This is an Open Access article under the terms of the Creative Commons Attribution License

(http://creativecommons.org/licenses/by/4.0), which permits unrestricted use, distribution, and reproduction in any medium, provided the original work is properly cited.

The license is subject to the Beilstein Journal of Organic Chemistry terms and conditions:

(https://www.beilstein-journals.org/bjoc)

The definitive version of this article is the electronic one which can be found at: doi:10.3762/bjoc. 14.76 